\title{
The Climatology of Blocking Anticyclones for the Northern and Southern Hemispheres: Block Intensity as a Diagnostic
}

\author{
JASON M. WIEDENMANN AND ANTHONY R. LUPO \\ Department of Atmospheric Sciences, University of Missouri-Columbia, Columbia, Missouri \\ Igor I. Mokhov And Elena A. Tikhonova \\ A.M. Oboukhov Institute of Atmospheric Physics, Russian Academy of Sciences, Moscow, Russia
}

(Manuscript received 30 July 2001, in final form 6 June 2002)

\begin{abstract}
A 30-yr climatology of blocking events was compiled by stratifying the data into seasonal and three regional categories for both the Northern and Southern Hemispheres using the NCEP-NCAR reanalyses. Several characteristics of blocking anticyclones were included in the study and these were frequency of occurrence, preferred formation regions, duration, blocking days, and intensity. The block intensity (BI) calculation was modified successfully from a previous study in order to automate the procedure for use with large datasets, and it is applied for the first time to derive a long-term observational record of this quantity. This modification also makes BI suitable for use as a diagnostic tool. Blocking events in the Northern (Southern) Hemisphere were the most persistent and strongest during the cold season and over the Atlantic (Pacific) region, as found using BI to measure intensity.

The characteristics of blocking events derived in this study were compared to previous long-term climatological studies and across each hemisphere. It was found that the temporal and spatial distributions in both hemispheres were similar to those of longer-term studies. The interannual variability of blocking was also examined with respect to ENSO-related variability for the entire blocking year. It was found that Northern (Southern) Hemisphere blocking events were stronger and more frequent during La Niña (El Niño) years, a result that is consistent with cyclone variability in each hemisphere. Additionally, these results were compared with previously published studies of interannual variability in blocking occurrence.
\end{abstract}

\section{Introduction}

The climatological behavior of blocking anticyclones is a topic that has been explored extensively recently. Long-term (30 yr or more) climatologies that were derived by Triedl et al. (1981), Lejenas and Okland (1983), or Gruza and Korovkina (1991a,b) described blocking characteristics such as frequency of occurrence and duration in the Northern Hemisphere (NH). Similar studies regarding the climatological behavior of blocking anticyclones in the Southern Hemisphere (SH) have been published over the last half-century beginning with van Loon (1956). Since then, several SH studies have followed (e.g., Lejenas 1984; Trenberth and Mo 1985; Tibaldi et al. 1994, Sinclair 1996; Renwick 1998; Kayano 1999; Marques and Rao 2000) as have related studies of SH large-scale flow regime behavior (e.g., Sinclair et al. 1997; Renwick and Revell 1999; Kidson 2000).

In general, the SH studies have described shorter-term

Corresponding author address: Anthony R. Lupo, Department of Atmospheric Sciences, 112 Gentry Hall, University of MissouriColumbia, Columbia, MO 65211.

E-mail: LupoA@missouri.edu climatologies than those of the $\mathrm{NH}$, used only a few climatological parameters, or confined the study of blocking to the cold season and/or the Pacific Ocean region. Thus, the authors are not aware of a 30-yr climatological study of SH blocking that includes an expanded list of blocking characteristics such as frequency of occurrence, duration, and preferred onset regions. Many short-term climatologies of NH blocking anticyclones also exist (e.g., Rex 1950; Tibaldi et al. 1994; Lupo and Smith 1995a, hereafter LS95a) that focus the study on one particular aspect of blocking. All of the blocking climatologies referenced above have been developed using subjective map analysis (e.g., Rex 1950; Triedl et al. 1981), objective criteria (e.g., Lejenas and Okland 1983; Lejenas 1984; Tibaldi et al. 1994), or thresholding methods (e.g., Shukla and Mo 1983).

LS95a developed a 3-yr NH blocking climatology that examined a more complete list of blocking characteristics of any previously published climatology, including not only frequency, primary locations of occurrence, and duration, but intensity and size as well. They also examined the intensity of the upstream surface cyclogenesis, which has been dynamically asso- 
ciated with the formation and maintenance of blocking events (e.g., Konrad and Colucci 1988; Tsou and Smith 1990; Lupo and Smith 1995b; Lupo 1997). In general, LS95a confirmed that NH blocking anticyclones occurred most frequently over the Pacific and Atlantic Ocean basins downstream of the primary storm tracks and during the cold season (October-April). Dole and Gordon (1983) were among the first to identify a distinct (third) primary block formation region over eastern Europe and western Asian continents, independent of Atlantic blocking, a result also found in LS95a. Additionally, they showed that cold season and oceanic region blocking events were stronger than warm season or continental blocking events. Finally, it was shown by LS95a that there was a correlation (significant at the $95 \%$ confidence level) between the deepening rate of the preceding upstream cyclones and the block intensity.

In general, earlier studies of SH blocking anticyclones have shown that these occur almost exclusively over the Pacific Ocean basin predominantly during the cold season (May-September). Studies such as Trenberth and Mo (1985), Marques and Rao (1999), and Frederiksen (2000) demonstrated that the formation and maintenance of blocking events in the $\mathrm{SH}$ are associated with synoptic and large-scale dynamics similar to their NH counterparts. Their climatological behavior, however, may be quite different (e.g., Lejenas 1984) in the SH.

Recently, quite a few studies (e.g., Renwick and Wallace 1996; Mokhov and Petukhov 1997; Chen and van den Dool 1997; Renwick 1998; Watson and Colucci 1999; Mokhov and Tikhonova 2000; Marques and Rao 2000; Shabbar et al. 2001) have examined the interannual variability of blocking in each hemisphere for selected seasons and in selected regions with respect to phenomena such as ENSO or the North Atlantic Oscillation (e.g., Shabbar et al. 2001). Renwick and Wallace (1996), who focus only on the cold season NH Pacific region, found that blocking activity tends to be suppressed in El Niño years. Watson and Colucci (1999), who examine only cold season $\mathrm{NH}$ blocking, found different results in that blocking is enhanced (suppressed) in the Pacific (Atlantic) region during El Niño years. They also demonstrate that in La Niña years blocking is enhanced (suppressed) over the Atlantic (Pacific) Ocean basin. The discrepancies between these studies may be a function of the blocking and/or ENSO definitions used and the length of the defined cold or winter season (e.g., Mokhov and Tikhonova 2000; Mokhov et al. 2001). In the SH, Renwick (1998) and Marques and Rao (2000) find that blocking was enhanced (suppressed) during El Niño (La Niña) years. Renwick (1998) and Renwick and Revell (1999) found strong interannual variability during the SH spring and summer season. Marques and Rao (2000) found strong interannual variability in the spring (fall) over the southeast (southwest) Pacific.

This work had two main objectives. The first (section 3) was to develop long-term comprehensive $\mathrm{NH}$ and $\mathrm{SH}$ climatologies for a more recent $30-y r$ period than previously published using methodologies similar to LS95a (see also Lupo et al. 1997), thus extending their work. In meeting the first objective, the block intensity calculation published in LS95a was automated successfully for use with archived gridded datasets. This necessary analysis of long-term climatologies in both hemispheres and long-term variations in blocking characteristics from observations will provide a consistent basis of comparison for similar studies that will be derived from general circulation models (e.g., Lupo et al. 1997). Additionally, no long-term objective climatologies of block intensity currently exist (Mokhov et al. 2001). The second objective (section 4) was to examine interannual variability in the climatological character of blocking associated with ENSO-related variability in both hemispheres. This study will examine blocking events throughout the year using more characteristics than previously published. A discussion of the results, including the implications drawn from the intensity climatology and an analysis of simultaneous blocking events, are presented in section 5 .

\section{Data and methodology}

\section{a. Data}

The dataset used in this study was the National Centers for Environmental Prediction-National Center for Atmospheric Research (NCEP-NCAR) gridded reanalyses, which are described in more detail by Kalnay et al. (1996). These analyses are archived at NCAR and are available from the NCAR mass-store facilities in Boulder, Colorado. The 0000 and 1200 UTC NCEPNCAR reanalyses used here for the calculations are the $500-\mathrm{hPa}$ gridded $\left(2.5^{\circ}\right.$ lat $\left.\times 2.5^{\circ} \mathrm{lon}\right)$ heights available at 6-h intervals. The plotted $500-\mathrm{hPa}$ heights reanalysis maps were also accessed through the NCEP Web site. ${ }^{1}$

The characteristics of the blocking events were stratified by season and region as in LS95a (and in Lupo et al. 1997), and these definitions for the NH are shown in Table 1. Equivalent SH seasons and regions are shown in Table 1 as well. The NH (SH) "blocking year" was defined to start with 1 July (1 January), and the 30-yr period of study encompassed the years from July 1968 to June 1998 (January 1970-December 1999). A 30-yr period was chosen in order to compare these results with those of earlier long-term NH blocking climatologies. No comparable 30-yr SH blocking climatology has been published. The blocking characteristics compiled in this study were number of events, duration, onset location, and blocking intensity (BI). The block intensity characteristic is described in section $2 b$.

\footnotetext{
${ }^{1}$ wesley.wwb.noaa.gov/ncep_data/index.htm/
} 
TABLE 1. Regional domains and seasons used in this investigation.

\begin{tabular}{|c|c|c|c|c|c|}
\hline Season & $\begin{array}{l}\text { Months } \\
(\mathrm{NH})\end{array}$ & $\begin{array}{l}\text { Months } \\
(\mathrm{SH})\end{array}$ & Regional domain & $\begin{array}{l}\text { Longitudinal boundaries } \\
\qquad(\mathrm{NH})\end{array}$ & $\begin{array}{l}\text { Longitudinal } \\
\text { boundaries } \\
\text { (SH) }\end{array}$ \\
\hline Summer & Jul-Sep & Jan-Mar & & & \\
\hline Autumn & Oct-Dec & Apr-Jun & Atlantic & $80^{\circ} \mathrm{W}-40^{\circ} \mathrm{E}$ & $60^{\circ} \mathrm{W}-30^{\circ} \mathrm{E}$ \\
\hline Winter & Jan-Mar & Jul-Sep & Pacific & $140^{\circ} \mathrm{E}-100^{\circ} \mathrm{W}$ & $130^{\circ} \mathrm{E}-60^{\circ} \mathrm{W}$ \\
\hline Spring & Apr-Jun & Oct-Dec & Continental $(\mathrm{NH}) /$ Indian $(\mathrm{SH})$ & $100^{\circ}-80^{\circ} \mathrm{W}$ and $40^{\circ}-140^{\circ} \mathrm{E}$ & $30^{\circ}-130^{\circ} \mathrm{E}$ \\
\hline
\end{tabular}

\section{b. Methodology}

The blocking criteria of LS95a were used here and, briefly, they define a blocking event as follows.

1) The Rex (1950) criteria must be satisfied for an anticylonic flow region at $500 \mathrm{hPa}$ with the exception that the minimum duration must be 5 days (Triedl et al. 1981).

2) A negative or small positive Lejenas and Okland (1983) index must be present on a Hovmöller diagram in the $\mathrm{NH}$ [for the $\mathrm{SH}$ we use Lejenas (1984)].

3) Conditions 1 and 2 must be statisfied together from $24 \mathrm{~h}$ after onset to $24 \mathrm{~h}$ before termination.

4) The anticyclone should be poleward of $35^{\circ} \mathrm{N}$ or $30^{\circ} \mathrm{S}$ and the ridge should have an amplitude of greater than $5^{\circ}$ latitude.

5) Block onset is described to occur when condition 4 and either conditions 1 or 2 are met.

6) Termination is designated at the time the event fails condition 5 for a $24-\mathrm{h}$ period or longer.

The Lejenas and Okland (1983) criterion (LO index) is a variation of the zonal index plotted on a time-longitude or Hovmöller diagram, where negative values tend to represent blocking events. LS95a found that persistent weak "nontranslating" LO index values could also represent blocking since the event may not be centered at the particular latitude specified in using the Lejenas and Okland $\left(1983,60^{\circ}\right.$ and $\left.40^{\circ} \mathrm{N}\right)$ or Lejenas $\left(1984,35^{\circ}\right.$ and $\left.50^{\circ} \mathrm{S}\right)$ criterion. Since the LO index as defined above was used here, a subjective appraisal of potential blocking events was necessary in order to reject features that are clearly not blocking anticyclones.

In LS95a, BI was calculated by normalizing the central height value using a subjectively determined contour line that represented the flow pattern. The value was

TABLE 2. An example of the relationship between BI and localized height gradients, where MZ in (1) is assigned a constant value of $5750 \mathrm{~m}$.

\begin{tabular}{ccc}
\hline \hline $\begin{array}{c}\text { Value of RC } \\
(\mathrm{m})\end{array}$ & $\begin{array}{c}\text { Difference } \\
\text { between MZ } \\
\text { and RC in Eq. (1) (m) }\end{array}$ & BI \\
\hline 5650 & 100 & 1.8 \\
5600 & 150 & 2.7 \\
5550 & 200 & 3.6 \\
5500 & 250 & 4.5 \\
5450 & 300 & 5.5 \\
5400 & 350 & 6.5 \\
\hline
\end{tabular}

then scaled in order that BI values rated from 1 to 10 , with increasing values being stronger, and as given by LS95a was

$$
\mathrm{BI}=100.0[(\mathrm{MZ} / \mathrm{RC})-1.0] .
$$

In (1) $\mathrm{MZ}$ was the maximum 500-hPa height in the closed anticyclone region or on a line associated with the ridge axis, and $\mathrm{RC}$ the subjectively chosen representative contour.

The BI calculation was modified here in order to automate the procedure, such that $\mathrm{RC}$ was replaced with the following:

$$
\mathrm{RC}=\frac{\frac{\left(Z_{u}+\mathrm{MZ}\right)}{2}+\frac{\left(Z_{d}+\mathrm{MZ}\right)}{2}}{2},
$$

where $Z_{u}\left(Z_{d}\right)$ represents the lowest height value in the trough axis upstream (downstream) of the block center at the same latitude. Thus, the new definition normalizes the central height value using a mean "contour" estimated across the area encompassed by the upstream and downstream troughs at the same latitude as the block center. This results in BI values that are proportional to the height gradients in the region of the block (see Table 2) as BI is larger during the cold season or when the NH height gradients are larger (LS95a; Lupo et al. 1997). Thus, BI can be used as a diagnostic for examining the relative strength of large-scale flow regimes for each hemisphere within blocking regions, particularly when comparing observations to model results (e.g., Lupo et al. 1997).

The automated procedure was then tested by applying the new methodology to the LS95a blocking events and comparing the objective BI calculations to the subjective BI values. The new procedure produced weaker BI values (3.04 vs. 3.55); however, the rationale used to stratify the 30 -yr sample by weak $(\mathrm{BI}<2.0)$, moderate $(2.0$ $<\mathrm{BI}<4.3$ ), and strong (BI > 4.3) blocking events was consistent with LS95a. Briefly, moderate blocking events are defined as those that fell within one standard deviation (1.15) of the 30-yr mean intensity (3.15), while the rest were labeled as either strong or weak (Fig. 1a). In the SH, BI values were derived and analyzed in the same manner and these produced normally distributed intensity values (Fig. 1b). However, BI values in the $\mathrm{SH}$ were weaker than those in the $\mathrm{NH}(2.8$ vs. 3.1), in general, and the method of classifying these can be described as follows; weak $(\mathrm{BI}<2.0)$, moderate 

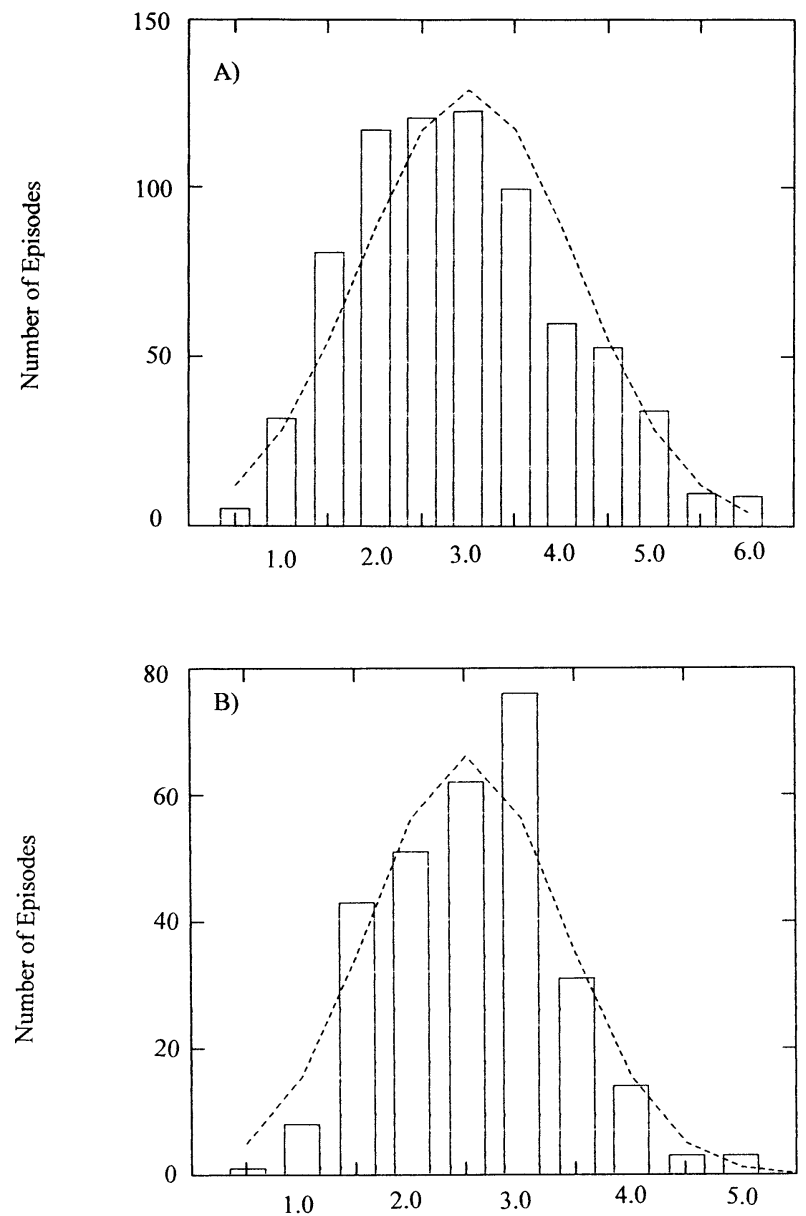

Intensity

FIG. 1. A histogram of the number of blocking events (ordinate) vs. block intensity (abscissa) for the total 30-yr sample of (a) Northern and (b) Southern Hemisphere blocking events. Each number represents an intensity "bin" (e.g., 1 represents events of intensity 1.01.49). The dashed line represents a fitted normal distribution [see Neter et al. (1988), p. 212, Eq. (7.5)].

$(2.0<\mathrm{BI}<3.6)$, and strong $(\mathrm{BI}>3.6)$. The standard deviation for SH blocking events was 0.80 .

Statistical tests were carried out only on sufficiently large samples in order to determine which results were significant at standard levels of confidence $(90 \%, 95 \%$, and $99 \%$ ), and details about these tests can be found in any basic statistical textbook (e.g., Neter et al. 1988). A simple two-sided "standardized test statistic" $\left(z^{*}\right)$ was used for the comparison of sample means for block occurrence, blocking days, and BI assuming a standard normal distribution. Correlations were tested using a $Z$ score test found in the same text and assuming the null hypothesis or that there was no a priori relationship between the two variables. Histograms or probability density distributions for subsets of blocking durations and intensities were tested using the chi-square goodness-of-fit test. For this test, the total observed (unap-
TABLE 3. A list of years in this study separated by ENSO phase.

\begin{tabular}{ccc}
\hline \hline La Niña (LN) & Neutral (NEU) & El Niño (EN) \\
\hline 1970 & 1968 & 1969 \\
1971 & 1974 & 1972 \\
1973 & $1977-81$ & 1976 \\
1975 & $1983-85$ & 1982 \\
1988 & 1989 & 1986 \\
1998 & 1990 & 1987 \\
1999 & $1992-96$ & 1991 \\
& & 1997 \\
\hline
\end{tabular}

proximated) sample distributions served as the "standard" or "expected" frequency when testing for interannual variability. This is preferable to using an approximated distribution since the actual observations may not adequately be represented by such distributions (e.g., Lupo et al. 1997). Also, testing the distributions of blocking characteristics, rather than simply testing the means, for interannual variability is more informative, since the sample size is larger, making the statistical conclusions more robust.

The interannual variability of blocking events was examined by partitioning the data by ENSO phase. ENSO is defined using the Japan Meteorological Agency (JMA) index, and a complete description can be found by accessing the Center for Ocean and Atmospheric Prediction Studies (COAPS) Web site. ${ }^{2}$ A list of El Niño (EN) and La Niña (LN) years is shown in Table 3, and the JMA index classifies years as EN, LN, and neutral (NEU) based on running mean Pacific Ocean basin SST anomaly thresholds $\left(4^{\circ} \mathrm{S}-4^{\circ} \mathrm{N}, 150^{\circ}-90^{\circ} \mathrm{W}\right.$, the Niño-3 region). An ENSO year is defined by the JMA as starting in October and ending with September of the next year. However, in order to ensure that the ENSO year encompassed the time of the blocking year when most events occurred, it was necessary to adjust the ENSO definition backward for the NH (SH) to start with the month of the corresponding to the start of blocking year (fall season). As the results will show, this adjustment will not adversely affect the annual results substantially, especially when comparing to previous work. Also, ENSO conditions begin to emerge during the NH summer and fall over the western and central tropical Pacific Ocean (west of the Niño-3 region), and this is the time of the year when blocking is most prevalent in the SH. It should be noted, however, that the choice of ENSO definition and subsequent modifications can influence the interpretation of seasonal results for climatological studies [e.g., hurricanes; see Pielke and Landsea (1999)]. Also, a comparison of the results in section 4 to those of Renwick (1998), Renwick and Revell (1999), and Marques and Rao (2000) may be at least be indicative partially of the sensitivity to choice of ENSO definitions, since these publications use a definition that only classifies years as "warm or cold"

\footnotetext{
${ }^{2}$ www.coaps.fsu.edu.
} 
TABLE 4. Regional and seasonal distribution of (a),(c) the number of blocking events/average duration in days of each blocking event, and (b),(d) the number of blocking days.

\begin{tabular}{lccccc}
\hline \hline Region & Summer & Fall & Winter & Spring & Total \\
\hline (a) Number of events/average duration $(\mathrm{NH})$. \\
All events & $156 / 7.6$ & $159 / 8.1$ & $215 / 8.9$ & $215 / 7.8$ & $745 / 8.2$ \\
Atlantic & $61 / 7.7$ & $97 / 8.5$ & $116 / 9.3$ & $110 / 8.0$ & $384 / 8.5$ \\
Pacific & $38 / 7.0$ & $36 / 7.2$ & $68 / 8.4$ & $57 / 7.2$ & $199 / 7.5$ \\
Continental & $57 / 8.0$ & $26 / 8.0$ & $31 / 8.3$ & $48 / 8.2$ & $162 / 8.1$ \\
(b) Total number of blocking days & $(\mathrm{NH})$. \\
All events & 1192 & 1290 & 1903 & 1685.5 & 6070.5 \\
Atlantic & 469 & 824.5 & 1075 & 884.5 & 3253 \\
Pacific & 264.5 & 258.0 & 569.5 & 409 & 1501 \\
Continental & 458.5 & 207.5 & 258.5 & 392 & 1316.5 \\
(c) Number of events/average duration $(\mathrm{SH})$. & & \\
All events & $37 / 6.4$ & $104 / 7.5$ & $97 / 7.8$ & $54 / 6.7$ & $292 / 7.3$ \\
Atlantic & $2 / 5.5$ & $9 / 6.2$ & $11 / 5.8$ & $7 / 5.8$ & $29 / 5.9$ \\
Pacific & $34 / 6.4$ & $81 / 7.8$ & $80 / 8.2$ & $41 / 6.9$ & $236 / 7.6$ \\
Indian & $1 / 5.0$ & $14 / 7.1$ & $6 / 5.8$ & $6 / 6.7$ & $27 / 6.6$ \\
(d) Total number of blocking days $(\mathrm{SH})$. & & \\
All events & 235 & 783 & 755.5 & 361.5 & 2135 \\
Atlantic & 11 & 55.5 & 63.5 & 40.5 & 170.5 \\
Pacific & 219 & 628 & 657 & 281 & 1785 \\
Indian & 5.0 & 99.5 & 35 & 40 & 179.5 \\
\hline \multicolumn{7}{c}{}
\end{tabular}

events (former studies) or El Niño or La Niña events (latter studies).

\section{Characteristics of $\mathrm{NH}$ and $\mathrm{SH}$ blocking events}

\section{a. NH blocking}

In this section we will only briefly describe our results since 30-yr blocking climatologies of the NH have been published previously. This section will focus on results that are not commented on frequently or at all by previous long-term climatologies (block intensity and simultaneous blocking events), or that contradict the findings of previous studies, including LS95a.

In the 30-yr period, 745 blocking events were identified, which represents an annual average of about 25 events (Table 4a). While this represents a greater number of blocking events annually than found by, for example, Triedl et al. (1981) or Lejenas and Okland (1983) (21 events per year), this result is not statistically significant at standard levels of confidence. Thus, the greater number of events found here may be, at least partially, a reflection of differences in the criterion applied and/or the superior quality of the newer data set used.

Examining the climatological characteristics of blocking events such as occurrences, blocking days, durations, and the preferred block formation locations in the 30-yr sample (Tables 4a,b and Figs. 1a-3a) show that the results are similar to those of previous studies. The regional distribution of these characteristics and their seasonal variations were similar as well (e.g., more blocking events occur during the cold season and they are stronger and more persistent during that season). The exception to this rule was the block intensities (Ta-
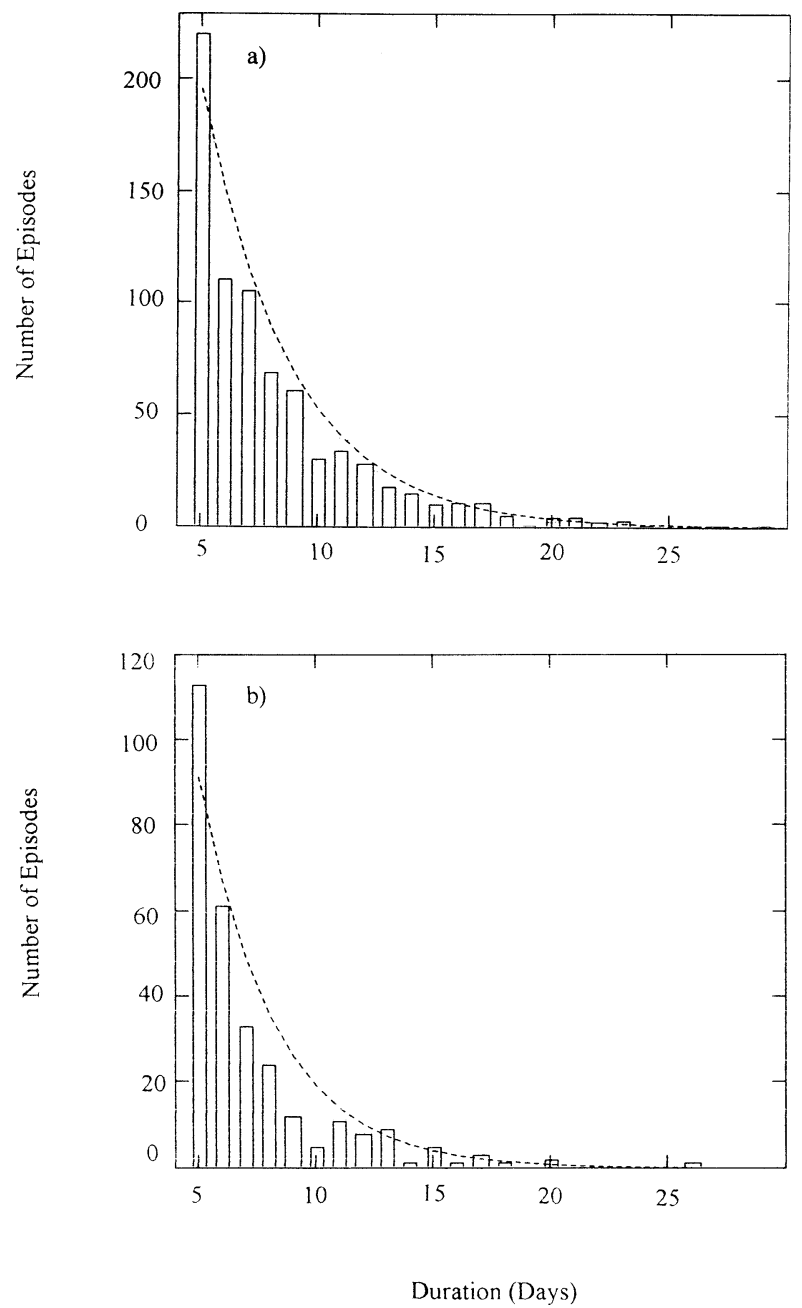

FIG. 2. A histogram of the number of blocking events (ordinate) vs. block intensity (abscissa) for the total 30-yr sample of (a) Northern and (b) Southern Hemisphere blocking events. The dashed line represents a fitted exponential distribution [see Neter et al. (1988), p. 221, Eq. (7.13)].

ble 5a), as described in section 2. Also, the distribution of block intensities has the form of normally distributed data, but this result is significant at a level just under $90 \%$ confidence. Additionally, the most persistent events were Atlantic region events, while most of the strongest blocking occurrences were Pacific region events (e.g., Mokhov et al. 2001).

LS95a also discussed the total number of blocked days, which is the difference between the sum of the three regional totals (Table $4 \mathrm{~b}$ ) and the number of days for which more than one blocking event was present concurrently (simultaneous blocking). As expected, these numbers were greater here owing to the larger number of blocking events found. The average number of blocked and simultaneous blocking days per year found here was 170.5 and 31.9. Thus, in the NH, blocking events were found to occur on $46.7 \%$ of the days during a given year, and $8.7 \%$ of the days annually had 

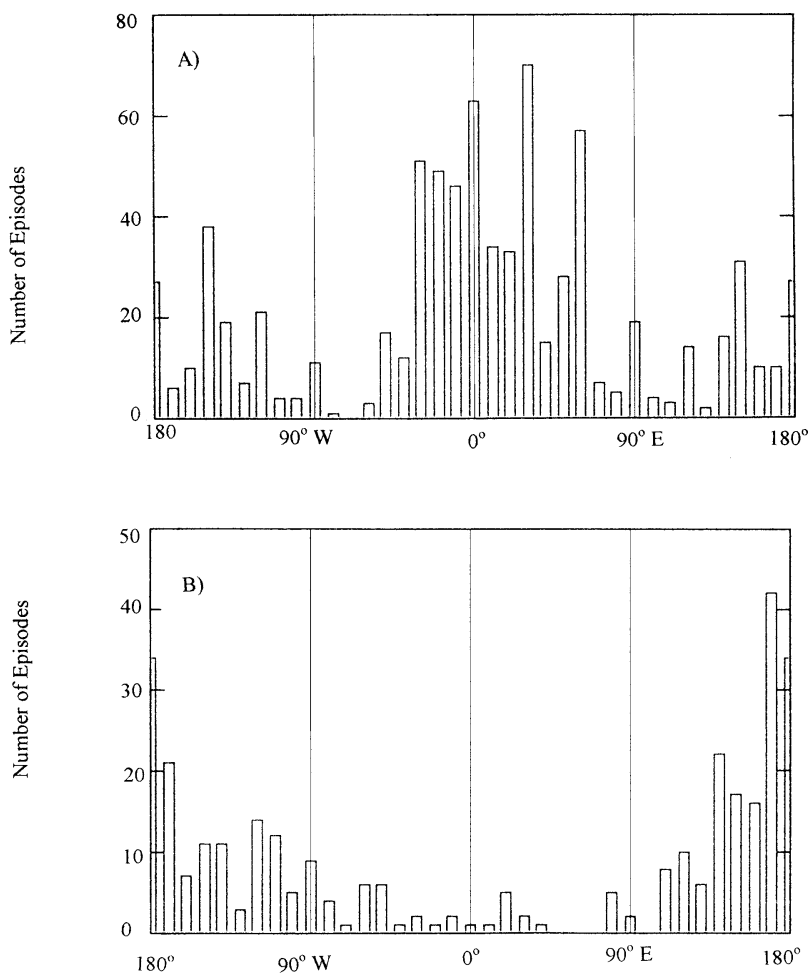

Longitude

FIG. 3. A histogram of the number of block formations (ordinate) vs. longitude (abscissa) for the 30-yr sample of (a) $\mathrm{NH}$ and (b) $\mathrm{SH}$ blocking events.

simultaneously occurring events present. Both of these results are consistent with those of Lejenas and Okland (1983). The ratio of simultaneous blocking days to blocked days found here was similar to that found by LS95a, or 0.185 and 0.175 , respectively.

\section{b. SH blocking}

Over the 30-yr period, there were 292 SH blocking events identified, which represents a mean of about 10 (9.7) events annually (Table 4c). Thus, in the SH, blocking events occurred only $40 \%$ as often than in the $\mathrm{NH}$, or $35 \%$ of the time comparatively when measured by the number of days (Table 4d). These results compare favorably with the shorter-term climatology of Lejenas (1984). The majority of these blocking events (69\%) and blocking days (72\%) (Tables 4c,d) occurred within the six months of the cold season (April-September). This is similar to the annual distribution of blocking events found in other studies, but it represents a sharper cold season peak than that found for the NH. By comparing favorably to previously published studies, these results suggest that the well-documented problem of out-of-phase SH observations (PAOBs) from 1979 to
TABLE 5. Block intensities for the (a) Northern Hemisphere and (b) Southern Hemisphere.

\begin{tabular}{lccccc}
\hline \hline \multicolumn{1}{c}{ Region } & Summer & Fall & Winter & Spring & Total \\
\hline (a) Northern Hemisphere & & & & \\
All events & 2.13 & 3.69 & 3.95 & 2.68 & 3.15 \\
Atlantic & 2.28 & 3.77 & 4.07 & 2.37 & 3.37 \\
Pacific & 2.11 & 3.76 & 4.05 & 2.60 & 3.14 \\
Continental & 1.99 & 3.30 & 3.28 & 2.68 & 2.63 \\
(b) Southern Hemisphere & & & & \\
All events & 2.60 & 2.94 & 2.84 & 2.71 & 2.82 \\
Atlantic & 2.67 & 2.88 & 3.42 & 3.32 & 3.18 \\
Pacific & 2.62 & 2.95 & 2.77 & 2.60 & 2.78 \\
Indian & 1.80 & 2.93 & 2.67 & 2.74 & 2.79 \\
\hline
\end{tabular}

$1992^{3}$ has not caused a significant problem in identifying blocking events for our analysis. Studies published on the NCEP website that is cited in the footnote also suggest that the identification of blocking events is not hampered by the problem.

The blocking events found here occurred primarily within the Pacific region (81\%) (Table 4c, Fig. 3b), a result similar to Lejeans (1984). However, when comparing the number of blocking days to Renwick (1998) and Marques and Rao (2000), this study found fewer (more) blocking days than the former (latter) study. Blocking events were equally infrequent within the Atlantic region and Indian Ocean region averaging about one occurrence per year, and these results are consistent with other $\mathrm{SH}$ blocking climatologies. Pacific region blocking events were distributed throughout the year in a similar fashion to SH blocking as a whole (Table 4c). The Atlantic and Indian Ocean region events were both evenly distributed throughout the April-November period, while during the summer season only three occurrences were noted over the entire $30-\mathrm{yr}$ period of study (Table 4c, Fig. 3b).

The total number of blocked days during the 30-yr period was 1965 days. Thus, blocking events were present during $17.9 \%$ of the days annually, and there were 170 days ( $1.5 \%$ of all) in which there were simultaneous blocking events present. This represents a much smaller fraction of SH simultaneous blocking days than found in the $\mathrm{NH}$, and this issue will be discussed in more detail in section 5 .

The average duration of $\mathrm{SH}$ blocking events was slightly less than their NH counterparts (Table 4). Pacific blocking events were more persistent than either Atlantic or Indian Ocean region blocking episodes (Table 4c), but were comparable in duration to their NH Pacific region counterparts (Table $4 a$ ). Figure 2 b demonstrates that most blocking events persisted for 5-7 days, and

\footnotetext{
${ }^{3}$ PAOBs are the product of human analysts who estimate sea level pressure for the data-poor southern oceans based on satellite data, conventional data, and time continuity. The Web site that documents this problem with $\mathrm{SH}$ PAOBs is wesley.wwb.noaa.gov/paobs/ paobs.html.
} 

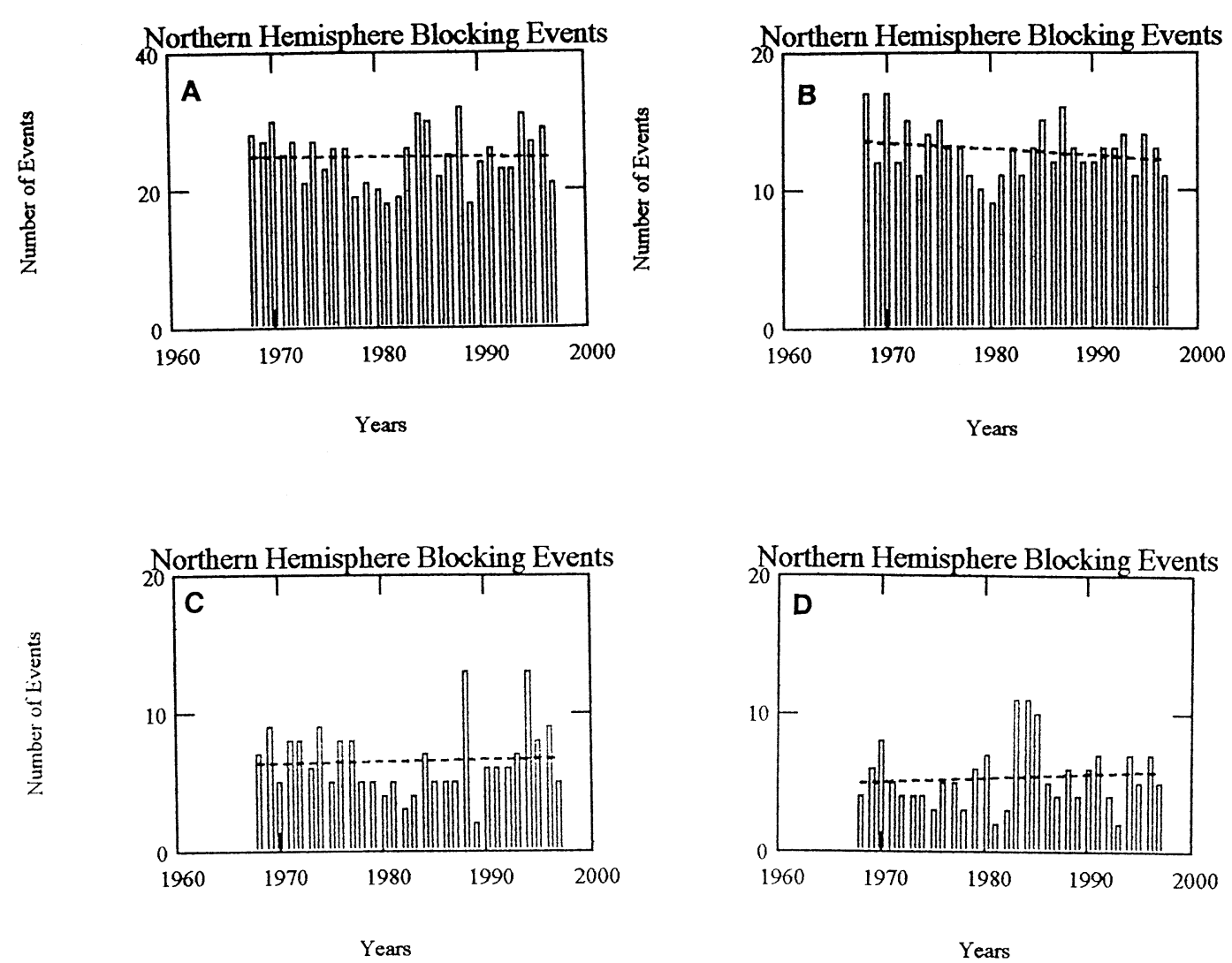

FIG. 4. A histogram of the number of NH blocking events (ordinate) vs year (abscissa) for the (a) total sample, (b) Atlantic, (c) Pacific, and (d) continental sectors. The dashed line is the linear trend line.

Table $4 \mathrm{c}$ demonstrates that winter and cold season blocking episodes were more persistent than those occurring in the summer and warm season. Both of these results were consistent with $\mathrm{NH}$ blocking.

The distribution of block durations shown in Fig. 2b is significantly different from that of the $\mathrm{NH}$ when testing using the chi-square goodness-of-fit test at the $95 \%$ confidence level. This difference is supported by examining the number of long-lived blocking events, or those events persisting for more than 10 days. There are more of these events in the NH (150 events or $20.1 \%$ of all) than in the SH (42 events or $14.4 \%$ of all). A closer examination of this result shows that few blocks in the Atlantic and Indian Ocean region are long-lived events (only three events in the combined regions). However, even in the Pacific region, the most persistent events are not as long lived as the most persistent $\mathrm{NH}$ Pacific region events.

An examination of the favored block onset regions (Fig. 4b) produces results that are generally similar to those of past studies (e.g., Lejenas 1984; Trenberth and Mo 1985; Sinclair 1996), and in the Pacific region there were two primary favored formation regions near $140^{\circ} \mathrm{E}-180^{\circ}$ and near $120^{\circ} \mathrm{W}$. Both of these regions were represented in all seasons (not shown), except during the spring when the western peak is prominent. In the
Atlantic and Indian Ocean regions, block formation regions were located close to the east of the South American and African continents (e.g., Lejenas 1984; Trenberth and Mo 1985; Sinclair 1986), and in the eastern Indian Ocean near Australia (Wright 1974). As in the $\mathrm{NH}$, all these regions were found just downstream of the SH storm tracks. The western South Pacific maximum is also associated with the well-known climatological split flow region found near and downstream of the Australia-New Zealand region (e.g., Trenberth and Mo 1985; Bals-Elsholz et al. 2001).

The block intensity analyses are summarized in Table $5 \mathrm{~b}$ and Fig. 1b. The SH block intensity values exhibited a normal distribution with respect to the mean, and this result was found to be significant at the $95 \%$ confidence level by fitting a normal distribution to the BI distribution and performing a chi-square goodness-of-fit test. There were $47(16.1 \%)$ strong and $53(18.1 \%)$ weak events found to be more than one standard deviation from the mean and these numbers are also consistent with that of normally distributed data. Cold season blocking events were stronger than warm season events within the $\mathrm{SH}$ as a whole and in every region (Table $5 \mathrm{~b}$ ), and this result is consistent with those for the $\mathrm{NH}$. When breaking down these numbers by region, Atlantic blocking events were the strongest events and they were 
TABLE 6. The mean (a) Northern Hemisphere and (b) Southern Hemisphere blocking characteristics by region, including number of events, block days, duration, and intensities (EN/NEU/LN years).

\begin{tabular}{|c|c|c|c|c|}
\hline Region & Number & Days & Duration & Intensity \\
\hline \multicolumn{5}{|c|}{ (a) Northern Hemisphere } \\
\hline Atlantic & $12.9 / 12.5 / 13.6$ & $113.1 / 105.3 / 111.2$ & $8.8 / 8.4 / 8.2$ & $3.30 / 3.36 / 3.50$ \\
\hline Pacific & $6.5 / 6.5 / 7.4$ & $45.3 / 49.4 / 59.2$ & $7.0 / 7.6 / 8.0$ & $2.80 / 3.35 / 3.01$ \\
\hline Continental & $4.7 / 5.8 / 5.2$ & $40.1 / 46.8 / 39.8$ & $8.4 / 8.1 / 7.7$ & $2.70 / 2.63 / 2.52$ \\
\hline Total & $24.1 / 24.8 / 26.2$ & $198.5 / 201.5 / 210.2$ & $8.2 / 8.1 / 8.0$ & $3.05 / 3.19 / 3.17$ \\
\hline \multicolumn{5}{|c|}{ (b) Southern Hemisphere } \\
\hline Atlantic & $1.0 / 1.0 / 0.7$ & $5.6 / 6.3 / 4.3$ & $5.6 / 6.0 / 6.0$ & $3.62 / 3.00 / 3.15$ \\
\hline Pacific & $9.0 / 7.8 / 7.0$ & $70.6 / 56.9 / 54.4$ & $7.8 / 7.3 / 7.8$ & $2.82 / 2.74 / 2.83$ \\
\hline Indian & $1.1 / 0.9 / 0.7$ & $7.8 / 6.2 / 3.8$ & $6.8 / 7.0 / 5.3$ & $2.78 / 2.88 / 2.57$ \\
\hline Total & $11.1 / 9.7 / 8.4$ & $83.9 / 69.4 / 62.4$ & $7.5 / 7.2 / 7.4$ & $2.89 / 2.78 / 2.83$ \\
\hline
\end{tabular}

of similar intensity to NH blocking episodes. Finally, an examination of the seasonal variations of the weak and strong episodes would show that, unlike NH blocking events, there was little seasonal variation in the percentage of events classified as weak (not shown). However, like NH blocking events, most strong SH blocking events (40 of 47) were cold season blocking events. The strongest blocking events were evenly distributed between the Pacific and Atlantic region.

\section{The interannual variability of blocking}

\section{a. NH blocking}

In the $\mathrm{NH}$ as a whole, there were no statistically significant trends in the annual occurrence of blocking (Fig. 4). In each region, there was a slight downward (upward) trend in block occurrences in the Atlantic (Pacific and continental) region(s) (Fig. 4); however, none of these regional changes were statistically significant.

Also, only slight ENSO-related variability was found for block occurrences as a whole in EN and $\mathrm{LN}$ years (Table $6 \mathrm{a}$ ), which represents $\mathrm{a}-3 \%$ and $+6 \%$ change in occurrence with respect to the annual mean, respectively. The sign of these changes agree with those of Watson and Colucci (1999). These differences in block occurrences are not statistically significant using the total 30-yr mean as the expected frequency, but the small sample size (number of years) inhibits these results from being robust in a statistical sense. A regional breakdown showed a similar result over the Pacific and Atlantic regions, in that more blocking events occurred during LN years than in EN and NEU years, and the Atlantic region result was similar to that found by Watson and Colucci (1999) for cold season blocking episodes. Within the continental region, there was more blocking in LA and NEU years, which agrees with the results of Mokhov and Tikhonova (2000).

Examining the number of blocking days and durations over the entire NH (Table 6a) shows that the increased number of events in LN years resulted in an increase in the number of days but not duration. However, when examining the Atlantic and continental regions, there was a decrease in duration without a significant change in the number of blocking days. Only in the Pacific region was there an increase in the number of events corresponding to an increase in days and duration. Examining the duration distributions in LN and EN years using the total 30-yr sample as the expected frequency (Fig. 2a) in the chi-square goodness-of-fit test would show that the EN and LN duration distributions (not shown) are different from the total sample at the $99 \%$ confidence level, but similar to each other. There were more short-lived (5 and 6 day) and very long-lived (1317 day) blocking episodes during EN and LN years versus those occurring in NEU years. While these results were statistically significant, the causes are not readily apparent and more studies would be needed for detailed diagnostics of this result. Nonetheless, the annual variations of block durations and intensities were similar in that cold season events were more persistent and stronger than warm season events in each ENSO phase.

The results in Table $6 \mathrm{a}$ suggest that $\mathrm{NH}$ blocking events were stronger during LN and NEU years than during EN years. This was especially true within the Atlantic and Pacific regions. To lend additional support to the difference in block intensity, the distributions were examined and compared to the total sample (Fig. 2a). Performing the chi-square test would show that while the NEU and LN distributions were similar to the total sample (no significant difference), the EN distribution was different from the total sample at the $99 \%$ confidence level. This concurs with the observation that in EN years a larger percentage of blocking episodes were classified as moderate events, but which were less than the 30-yr mean intensity (weak moderate). These results were similar within the Atlantic and Pacific Ocean basins as well.

\section{b. SH blocking}

The long-term change in the annual number of $\mathrm{SH}$ blocking events (Fig. 5) reveals that there was a downward linear trend in the number of events overall and within each $\mathrm{SH}$ region. This trend was significant at the 

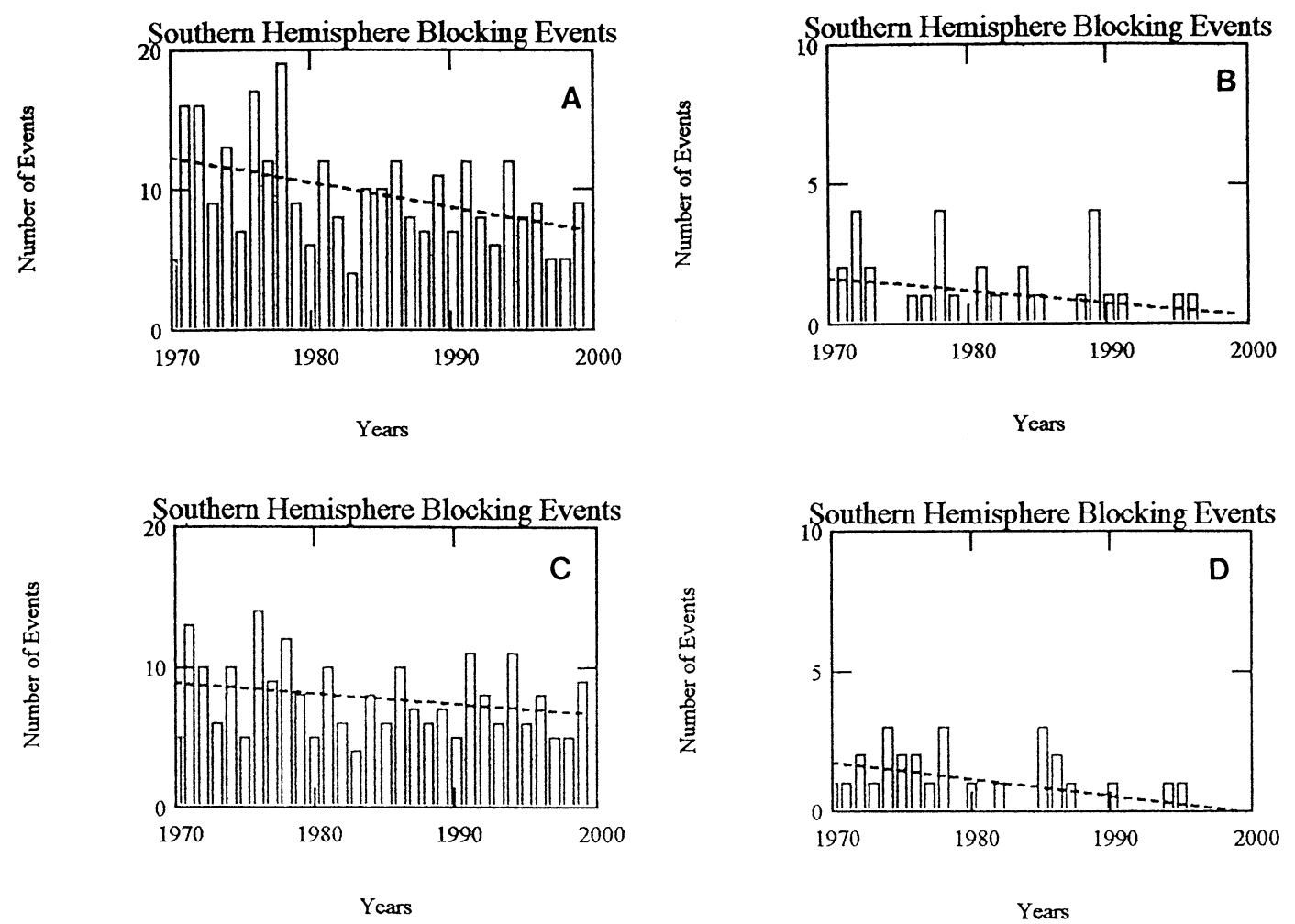

FIG. 5. As in Fig. 4, except for the SH.

95\% confidence level for the whole SH, and over each region except the Pacific, when using a simple $F$ test (e.g., Neter et al. 1988, chapter 19). A common problem with constructing linear trends is that these can be critically dependent on the values at the end points, but this result will be discussed further in section 5. Additionally, there were no significant long-term trends in the duration or intensity of SH blocking events (not shown).

Examining the ENSO-related variability shows that there were more blocking events occurring in general during EN years compared to LN or NEU years (Table $6 \mathrm{~b})$. None of these results were significant at the $90 \%$ confidence level, but to a lower degree of confidence. Additionally, the annual variation of block occurrences across each ENSO phase was similar to the hemispheric dataset as a whole as blocking was more frequent during the cold season than during the warm season (not shown). A discussion of Pacific region block occurrences would resemble those of the entire hemisphere. An examination of the variability within only the Atlantic and Indian Ocean regions, which have typically been neglected, showed that there were also more events occurring during EN years than compared LN years (Table $6 \mathrm{~b}$ ). The increased frequency of blocking events for EN years in the Pacific region agrees with the results of Renwick (1998), Renwick and Revell (1999), and Marques and Rao (2000), and the results of Renwick (1998) were found significant at the 95\% level.

The annual variation of duration and intensity was similar to that of the entire hemisphere as a whole for each phase (e.g., EN, LN, and NEU) in that cold season blocking events were more intense and persistent than warm season events (not shown). NH blocking events demonstrated greater interannual variability in their intensity than SH blocking (Table 6). Also, the number of simultaneous blocking days was greater during EN years than during $\mathrm{LN}$ years (2.1\% of all days vs. $1.1 \%$, respectively). It is noted here that during EN years, Atlantic and Indian region blocking events were stronger than those occurring during LN years. Additionally, Indian region blocking was much less persistent during LN years than during EN or NEU years (5 vs 7 days, respectively). Statistical testing was not performed here since the sample sizes were small.

The distributions for both $\mathrm{SH}$ block durations and intensities for each ENSO phase were tested versus the observed distributions in order to determine if there were any significant differences. When examining block intensities (not shown), the distribution of LN and EN blocking were different from the total distribution at the 97\% confidence interval. Further examination revealed that there were fewer (more) blocking events that were stronger than the hemispheric mean during LN (EN) years. The block duration distributions for LN blocking events were different from the hemispheric distribution (significant at the 95\% confidence level), while EN and NEU year duration distributions were similar to that of the hemispheric distribution. This result was due to the 
occurrence of a fewer number of long-lived blocking events during $\mathrm{LN}$ years.

\section{Discussion}

\section{a. Climatology}

The 30-yr climatology of blocking events in large measure supports the findings of previous short-term and longer-term climatologies for both hemispheres. While blocking was relatively infrequent, less persistent, and weaker in the SH when compared to blocking in the $\mathrm{NH}$, the annual variation in blocking characteristics are similar to that for the $\mathrm{NH}$. In the $\mathrm{SH}$, the predominance of Pacific region blocking is likely reflected in the wavenumber- 1 signal in the $500-\mathrm{hPa}$ height departures when examining the SH general circulation [see Hurrell et al. (1995), their Fig. 1.18]. However, Trenberth and Mo (1985) suggest that wavenumber 3 in the $500-\mathrm{hPa}$ height variances is generally associated with blocking, and this was supported in later studies (e.g., Renwick and Revell 1999). Thus, any explanation of the differences in the frequency, intensity, and duration in blocking between the $\mathrm{NH}$ and $\mathrm{SH}$ must at least address the issue of the relative infrequent occurrence of blocking in the Atlantic and Indian regions, and their tendencies to be less persistent.

The infrequent occurrence of SH blocking may be the result of different distributions in the relative importance of synoptic- and planetary-scale forcing, especially in the Atlantic and Indian regions. This issue was explored for NH Pacific and Atlantic region blocking events (Nakamura et al. 1997). It is also possibly the result of a smaller likelihood of developing a favorable phase relationship between SH synoptic- and planetary-scale waves that result in block formation. Given that there is strong intraseasonal variability over the entire year across the midlatitude SH general circulation (Hurrell et al. 1995, Fig. 1.19) that is suggestive of consistent cyclone activity, the latter explanation (or a combination of the two) may be more plausible.

Tsou and Smith (1990), Lupo (1997), and Lupo and Smith (1998) discuss the relative roles of synoptic- and planetary-scale dynamic and thermodynamic forcing, and the phase relationship between waves of these scales was discussed in these studies and Lupo and Bosart (1999) for observed NH blocking events. In particular, these observational studies demonstrate what theoretical studies have revealed (e.g., Kalnay-Rivas and Merkine 1981; Frederiksen 1982; Shutts 1983, 1986; Swanson 2001), namely, that the development of individual synoptic cyclones within one-half wavelength upstream of large-scale ridging provides a favorable phase relationship for resonant interaction between each scale. As the upstream cyclone develops due to dynamic (e.g., cyclonic vorticity advection or flux) and thermodynamic forcing processes, the forcing mechanisms contributing to cyclone development and downstream ridging are synergistically enhanced, resulting in anticyclonic vorticity transport into the developing or strengthening blocking event. This process, which is important for block development and maintenance, is illustrated in Fig. 6. It is suggested here that such interactions occur less often in the SH Atlantic and Indian Ocean regions, and that once a block develops, it is more difficult to maintain in those regions, thus accounting for their decreased longevity in those regions. However, more study of the dynamics for observed cases of blocking episodes and nonblocking periods would be needed in order to demonstrate the validity of the assertions made above regarding SH blocking.

The differences in the mean intensity of $\mathrm{NH}$ and $\mathrm{SH}$ blocking can be accounted for by examining the character of the mean 500-hPa flow (e.g., Hurrell et al. 1995, Figs. 1.17-1.20). If BI is proportional to the strength of the height gradients on the upstream and downstream flanks of blocking events, overall and seasonal mean BIs should be larger (smaller) in regions where the mean seasonal $500-\mathrm{hPa}$ flow field is more (less) meridional. The strongest NH blocking events, as measured by BI, occurred in the NH Atlantic and Pacific, and these are regions where the cold season mean flow is more meridional than for other regions of the globe (see Tables A2 and A4 of the appendix). A list of the strongest and most persistent blocking events and their corresponding regions (where $\mathrm{AR}=$ Atlantic region and $\mathrm{PR}=$ Pacific region) can be found in the appendix (Tables A1-A4).

Blocking events are local phenomena rather than globally occurring as demonstrated by Lejenas and Okland (1983), Lupo (1997), and Fournier (2000) using statistical methods, dynamic relationships, and wavelet analysis techniques, respectively. The presence of a simultaneous blocking episode was shown by Lupo (1997) to be the result of the coincidental interplay between large- and synoptic-scale forcing, and the associated wave-wave interactions, independently occurring in two different parts of the globe. Then it may be expected that there would be no appreciable change in the proportion of simultaneous blocking events found here for the $\mathrm{NH}$, when comparing to Lejenas and Okland (1983) and LS95a. However, in the SH, there were fewer simultaneous blocking days in terms of their raw number and their proportion of total days (e.g., fewer events, fewer opportunities for simultaneous occurrence; see section 3). This result would seem to support the assertion that blocking events are local events, and that simultaneous SH blocking episodes were statistically independent occurrences. This seems to be the case despite the predominance of wavenumber 3 in SH blocking cited above and would agree with $\mathrm{NH}$ observations. Trenberth and Mo (1985) concede, however, that more study is necessary to demonstrate conclusively that simultaneous SH blocking events are dynamically independent or locally occurring events.

Rex (1950), Quiroz (1987), and LS95a noted in a subjective evaluation that the most spectacular (stron- 


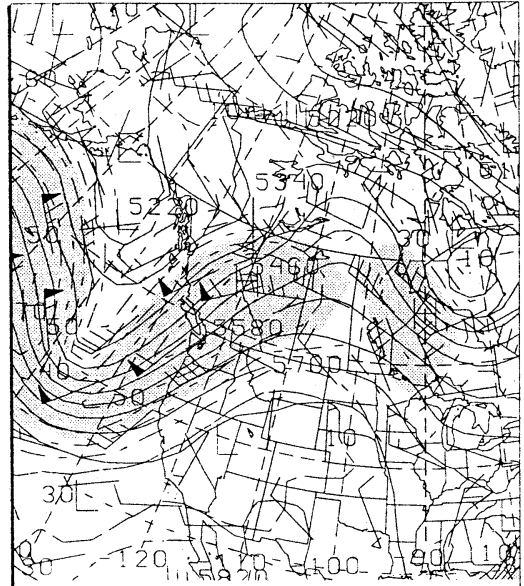

a)

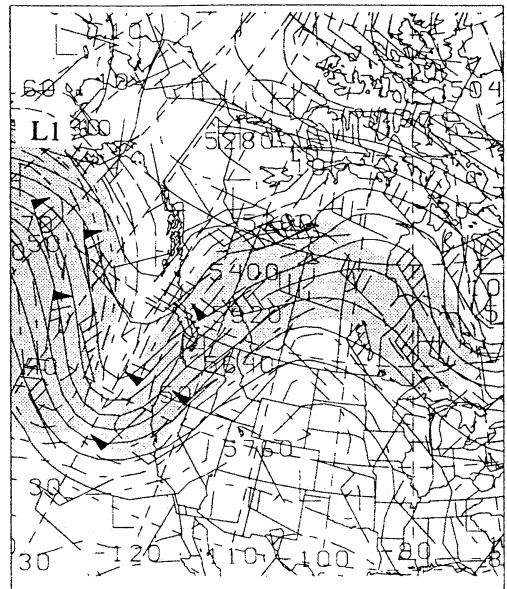

b) $800420 \quad 1200$ GMT

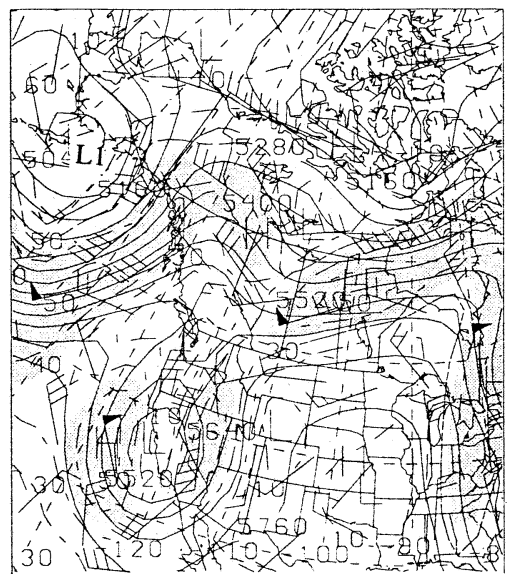

e)

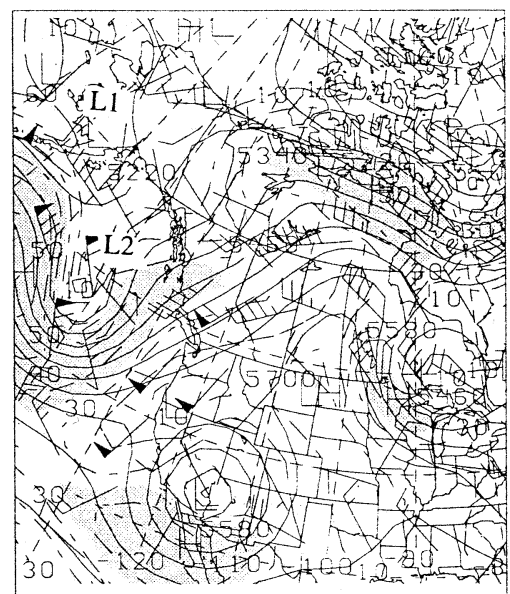

h) $800423 \quad 1200 \quad \mathrm{GMT}$
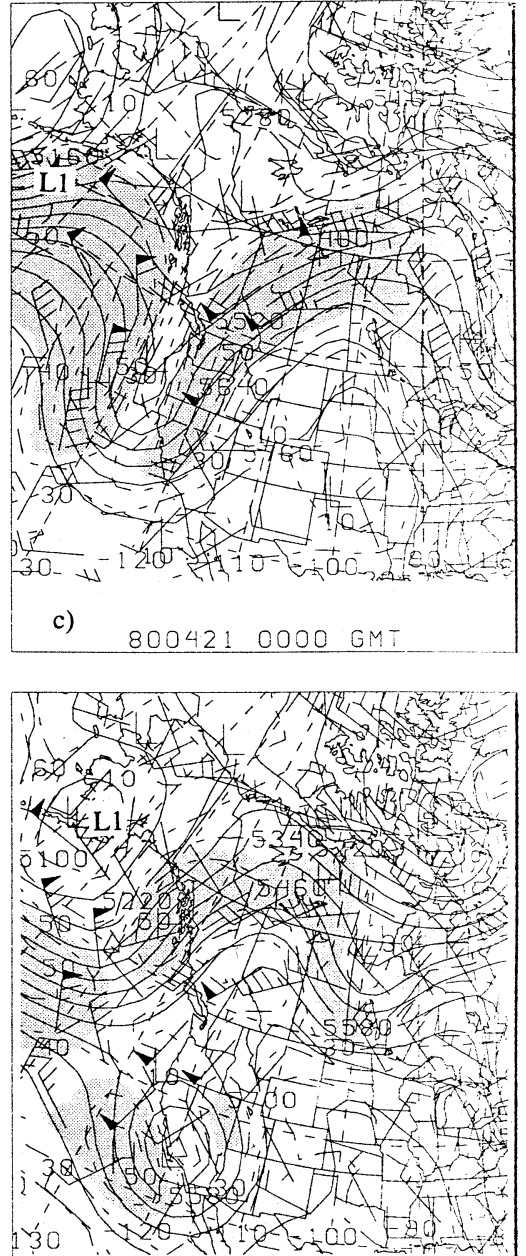

f)

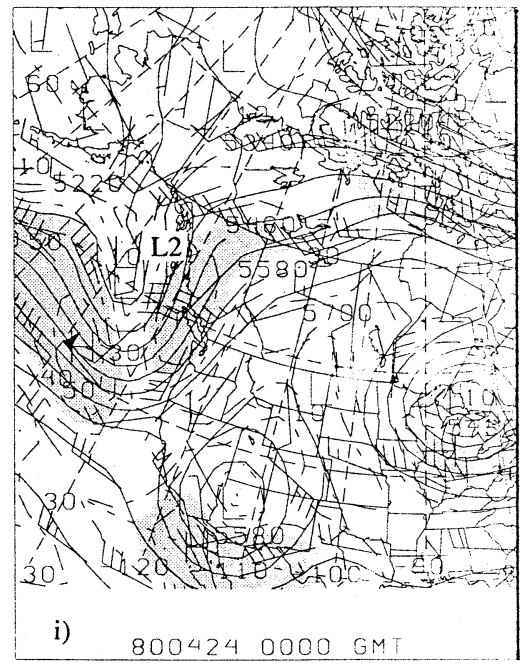

Fig. 6. (Adapted from Lupo and Bosart, 1999, their Fig. 10.) Horizontal distribution of 500-hPa heights (m) and 300-hPa wind (m s${ }^{-1}$ ) for (a) 0000 UTC 20 Apr 1980, (b) 1200 UTC 20 Apr, (c) 0000 UTC 21 Apr, (d) 1200 UTC 21 Apr, (e) 0000 UTC 22 Apr, (f) 1200 UTC 22 Apr, (g) 0000 UTC 23 Apr, (h) 1200 UTC 23 Apr, and (i) 0000 UTC 24 Apr. The heights (solid) are contoured every 60 m, and the winds (dashed) are contoured every $10 \mathrm{~m} \mathrm{~s}^{-1}$ and shaded for values above $35 \mathrm{~m} \mathrm{~s}^{-1}$. The wind barbs show wind direction and each feather and flag represents 10 and $50 \mathrm{~m} \mathrm{~s}^{-1}$ increments, respectively. Relevant surface lows are marked with an "L1" or "L2"; all others are upper air markers. 
gest) blocking events occurred in association with simultaneous blocking events. It can be shown that 8 out of the 10 (and 18 of the 22; not shown here) strongest blocking events were associated with another concurrently occurring blocking event in the $\mathrm{NH}$ (Table A2) classified as strong, or moderate but greater than the 30-yr mean intensity (strong moderate). The most dramatic case of simultaneous blocking as evaluated by the combined intensities of both events occurred in January 1991 (tenth strongest event, Table A2, was accompanied by a Pacific region event; $\mathrm{BI}=5.84$ ). This result would seem to contradict the contention that blocking is a locally occurring phenomenon, and many studies have demonstrated the contribution of large-scale waves in the life cycle of blocking events (e.g., Agayan and Mokhov 1989). But the simultaneously occurring blocking events studied by Lupo (1997) included one of the 20 strongest events found in our 30-yr period. Also, unlike in the $\mathrm{NH}$, there was no apparent relationship between simultaneously occurring SH blocking events and intensity. Additionally, Lejenas and Madden (1992) find that wavenumber-2 height anomalies are slightly amplified in the NH during blocking episodes. Thus, it is not entirely clear whether the enhanced intensity of simultaneous $\mathrm{NH}$ blocking events is the result of the wave-wave interactions described above or if the amplification of wavenumber 2 found by Lejenas and Madden (1992) is captured by BI.

A correlation of 0.16 between $\mathrm{BI}$ and duration was found using the 30-yr sample of $\mathrm{NH}$ blocking events and this was significant at the $99 \%$ confidence level. Thus, stronger blocking events were also longer-lived events. There was no correlation between BI and SH block durations. Additionally, the lack of a correlation between block duration and intensity in the $\mathrm{SH}$ may be the result of a fundamental difference between the two hemispheres in the relative contributions between the large- and synoptic-scale forcing that contributes to block maintenance. These interactions have been examined regionally [e.g., Trenberth and Mo 1985 (SH); Tsou and Smith 1990 (NH); Nakamura et al. 1997 (NH); Lupo 1997 (NH); Lupo and Smith 1998 (NH); Renwick and Revell 1999 (SH)], but none of these studies compare $\mathrm{NH}$ and $\mathrm{SH}$ dynamics as described above, or examine the relationship of the planetary- or synoptic-scale component of the flow to $\mathrm{BI}$ in individual blocking events.

\section{b. ENSO variations and long-term trends}

An examination of the ENSO-related interannual variability in $\mathrm{NH}$ and $\mathrm{SH}$ block occurrences yielded the following results. There were more blocking events within the NH, especially over the Pacific region during LN years. These results were similar to those found by other studies (e.g, Renwick and Wallace 1996; Chen and van den Dool 1997; Watson and Colucci 1999; Mokhov and Tikhonova 2000) but were not very robust in a statistical sense. Nonetheless, the results found here may still have an underlying physical explanation (e.g.,
Nicholls 2001) and this will be explored below. Also, Renwick and Wallace (1996) and Chen and van den Dool (1997) only examined winter season blocking (December-February). The former study also focused only on Pacific region blocking occurring within and near the Gulf of Alaska region. Watson and Colucci (1999) found more Pacific region blocking basinwide during EN years (September-May). However, our study bolsters the Pacific region results for both Renwick and Wallace (1996) and Watson and Colucci (1999) simply by adjusting the time periods and definition of the $\mathrm{Pa}$ cific Ocean basin examined here to match those of each of their studies (not shown). In the SH, there were more blocking events found during EN years (15\% more than the sample mean) than in LN years (15\% less than LN years than the sample mean). This SH ENSO-related interannual variability was found across all regions and was opposite to, and greater than, that found for $\mathrm{NH}$ blocking (e.g., Renwick and Wallace 1996).

Given the dynamic link between cyclones and block formation and maintenance described in section $5 \mathrm{a}$, it would be expected that variability in the storm tracks in both hemispheres may be associated with changes in the frequency of blocking. Then a possible rationale for the increase in blocking activity during one phase of ENSO may be provided by examining a 40-yr global climatology of cyclone frequencies (e.g., Key and Chan 1999). The increased $\mathrm{NH}$ blocking frequency in LN years may correspond to the $\mathrm{LN}$ year increase in cyclone activity over the midlatitude $\mathrm{NH}$ as found by the study above, as more cyclones may provide more opportunities for block formation. The more active $\mathrm{SH}$ Pacific blocking region during EN years is also consistent with the results of Key and Chan (1999), and they found that the South Pacific convergence zone (SPCZ) and the SH midlatitudes were more active during EN years. The SPCZ is the subtropical and midlatitude cyclogenetic region found near and downstream of the Australian region of the South Pacific (see Vincent 1994). The results of Renwick and Revell (1999) also demonstrate a dynamic connection between the SPCZ and Pacific region blocking through Rossby wave propagation. Additionally, they find strong ENSO related variations in the large-scale flow regimes there, which they speculate is also related to synopticscale variability, further bolstering these results.

Additionally, Renwick (1998) suggests that the interannual variability found in the occurrence of $\mathrm{SH}$ blocking is insensitive to the exact criterion of blocking chosen for study. Here it is suggested that these results are also not very sensitive to the ENSO definition used as well, as the definition used here was different from those of Renwick (1998), Renwick and Revell (1998), and Marques and Rao (2000), but similar results in block occurrences to all these studies were found here.

An examination of interannual variability in block intensity using the hemispheric distributions of BI revealed that blocking events were stronger during LN and NEU (EN) years than during EN (LN) years in the $\mathrm{NH}(\mathrm{SH})$ as a whole. The observation found here for fewer and 
weaker blocking events in the $\mathrm{NH}$, especially over the Pacific (and to some extent the Atlantic), region during ENSO years would be consistent with the results of Renwick and Wallace (1996). They show in their Fig. 3 that the 500-hPa height variances are smaller during EN years, which would imply more zonal flow over the North Pacific midlatitudes. Also, the blocking regions of the $\mathrm{NH}$ Pacific and Atlantic are shown in Hurrell et al. (1995) to be regions of strong interannual variability using 500$\mathrm{hPa}$ height fields and variances. These height variances alone only suggest variations in block occurrences, or intensities, or both. However, the results of this study provided a method for quantifying each variable separately, demonstrating the utility of BI as a diagnostic quantity. Additionally, LS95a found a correlation between BI and the cyclogenetic rate of the upstream cyclones. More specifically, stronger blocking events are associated with rapidly deepening cyclone events. If this correlation were established for a longer-term climatology, it may suggest that there are more rapid deepening cyclones in La Niña years as well. In the SH, no correlation was found between $\mathrm{BI}$ and block duration, thus stronger and longer-lived SH blocking events in EN years (section 4) are likely due to the greater cyclone frequencies found by Key and Chan (1999).

The long-term trend in SH block occurrence is consistent with the long-term trends in $500-\mathrm{hPa}$ heights as shown by Renwick and Revell (1999). They showed a long-term strengthening of the polar vortex and a general increase in the strength of zonal flow in the $\mathrm{SH}$ as implied by the long-term decrease (increase) in heights over the poles (midlatitudes and Tropics). Their trends are statistically significant everywhere except for the midlatitude Pacific Ocean region and match the trends in block occurrence found in section 4 . The trend toward more zonal flow would not be conducive to block formation necessarily since block formation requires the phasing of, and synergistic interaction between, cyclone-scale waves and long waves. However, increased zonal flow would, presumably, present fewer opportunities for these interactions to occur. In addition, Key and Chan (1999) found that the long-term trend for midlatitude $\mathrm{SH}$ cyclone frequencies was downward as well, which would also provide for fewer opportunities to generate blocking episodes.

\section{Summary and conclusions}

A 30-yr climatology for NH and SH blocking characteristics during a period covering the latter portion of the twentieth century was compiled. These data were stratified by season and region using the NCEP-NCAR reanalyses. The blocking anticyclone characteristics included here were frequency of occurrence, preferred formation regions, duration, blocking days, and intensity. The definition of block intensity (BI) was modified successfully from LS95a in order to automate the procedure for use with large datasets. The BI, coupled with raw block occurrences, provides an additional diagnos- tic tool in quantifying variability in the 500-hPa height fields. The BI can also be used to infer the relative strength of the zonal flow in blocking regions since this value is proportional to meridional height gradients in the blocking region. The results of this blocking climatology were then compared to previous long-term climatological studies and those of LS95a. Additionally, the interannual variability of blocking in both hemispheres was examined with respect to ENSO-related variability, and these results complemented, or compared favorably with, those of previous studies.

The relative infrequent occurrence of $\mathrm{SH}$ blocking compared to that of $\mathrm{NH}$ can be explained by the paucity of blocking events within the SH Atlantic and Indian Ocean regions. It is speculated that in these regions, there is a smaller likelihood of attaining a favorable phase relationship between synergistically amplifying synoptic- and large-scale waves. This, in combination with differing distributions in the relative importance or magnitude of synoptic- and planetary-scale forcing between blocking regions (e.g., Nakamura et al. 1997), may provide at least a partial rationale for the lack of blocking in these regions. Additionally, it was found here that in the $\mathrm{NH}$, stronger blocking episodes were longer lived, and the correlation between these two characteristics was statistically significant. No such correlation was found for the SH.

When examining mean or seasonal BI values, larger BIs were found in regions where the mean flow is more meridional. This can be shown by the tendency for $\mathrm{NH}$ Pacific and Atlantic region blocking events to be stronger than their SH counterparts. As in LS95a, cold season blocking events in both hemispheres were stronger than their warm season counterparts. Also, it was shown here that many of the strongest blocking events in the $\mathrm{NH}$ occurred within a "simultaneous" blocking episode, a result that supports the subjective observations of other studies. There was no corresponding association between simultaneously occurring events and intensity in the SH.

An examination of the interannual variability in the character of blocking events with respect to ENSO-related variability yielded the following results. There were more blocking events within the $\mathrm{NH}$, especially over the Pacific region during La Niña years. While these results were not statistically robust, they do support the results of other studies that used different definitions for ENSO. Additionally, it was found that blocking episodes in the NH La Niña and neutral years were more intense than events occurring in El Niño years, and these results were statistically significant at the $99 \%$ confidence level. In the $\mathrm{SH}$, there were more blocking events found during EN years than in LN years, and this result was found across all SH regions. The interannual variability in block occurrences may relate to variability in cyclone frequencies in both hemispheres, especially in the region of the SPCZ. An examination of the block durations and intensities does support the contention that SH blocking events were longer-lived and stronger during EN years. There was 
also more simultaneous SH blocking days during EN years than during LN years, while little significant interannual variability was noted in the mean blocking days, or primary locations of block formation found here. There was also a long-term trend in SH block occurrences that was found to be consistent with the long-term trends in SH 500-hPa heights.

Acknowledgments. This research was supported by a grant from the University of Missouri Research Board (Project Number URB-98-113). The authors would also like to acknowledge the support of the Russian Foundation for Basic Research. Also, the very helpful comments made by Dr. Francis Zwiers and the three anonymous reviewers substantially improved this manuscript, and the authors sincerely appreciate their efforts.

\section{APPENDIX}

TABLE A1. The 10 longest lived Northern Hemisphere blocking events in this study.

\begin{tabular}{rlll}
\hline \hline Rank & Event & Days & Region \\
\hline 1 & Dec 1995 & 29 & AR \\
2 & Jan 1996 & 27 & AR \\
3 & Apr 1973 & 26 & AR \\
4 & Oct 1987 & 24 & AR \\
5 & Jan 1974 & 23 & PR \\
6 & Dec 1982 & 23 & AR \\
7 & Sep 1996 & 22.5 & AR \\
8 & Sep 1968 & 22 & AR \\
9 & Jan 1989 & 21.5 & AR \\
10 & Feb 1983 & 21.5 & AR \\
\hline
\end{tabular}

TABLE A2. The strongest 10 Northern Hemisphere blocking events.

\begin{tabular}{cllcc}
\hline \hline Rank & Event & BI & Region & $\begin{array}{c}\text { Simulta- } \\
\text { neous? }\end{array}$ \\
\hline 1 & Feb 1991 & 6.42 & PR & Yes \\
2 & Mar 1996 & 6.4 & PR & Yes \\
3 & Nov 1997 & 6.31 & AR & No \\
4 & Feb 1989 & 6.2 & PR & Yes \\
5 & Jan 1985 & 6.17 & PR & Yes \\
6 & Dec 1996 & 6.16 & PR & Yes \\
7 & Jan 1979 & 6.09 & PR & No \\
8 & Dec 1983 & 6.08 & PR & Yes \\
9 & Feb 1975 & 6.08 & AR & Yes \\
10 & Jan 1991 & 5.91 & AR & Yes \\
\hline
\end{tabular}

TABLE A3. The 10 longest lived SH blocking events in this study.

\begin{tabular}{cllc}
\hline \hline Rank & Event & Days & Region \\
\hline 1 & Jul 1976 & 26 & PR \\
2 & May 1973 & 20.5 & PR \\
3 & Jun 1981 & 20 & PR \\
4 & Jul 1973 & 18 & PR \\
5 & Dec 1972 & 17.5 & PR \\
6 & Aug 1989 & 17 & PR \\
7 & Jun 1992 & 17 & PR \\
8 & Apr 1985 & 16 & PR \\
9 & Jun 1974 & 15.5 & PR \\
10 & Jun 1978 & 15.5 & PR \\
\hline
\end{tabular}

TABLE A4. The 10 strongest Southern Hemisphere blocking events.

\begin{tabular}{clccc}
\hline \hline Rank & Event & BI & Region & $\begin{array}{c}\text { Simulta- } \\
\text { neous? }\end{array}$ \\
\hline 1 & Oct 1995 & 5.40 & AR & No \\
2 & May 1991 & 5.30 & PR & No \\
3 & Sep 1996 & 5.00 & PR & No \\
4 & Jun 1995 & 4.83 & PR & No \\
5 & Aug 1984 & 4.64 & AR & Yes \\
6 & Apr 1980 & 4.54 & PR & No \\
7 & Sep 1972 & 4.36 & AR & No \\
8 & Aug 1977 & 4.32 & AR & Yes \\
9 & Jul 1994 & 4.32 & PR & No \\
10 & May 1985 & 4.29 & PR & No \\
\hline
\end{tabular}

\section{REFERENCES}

Agayan, G. M., and I. I. Mokhov, 1989: Quasistationary autumn regimes of the Northern Hemisphere atmosphere in FGGE. Atmos. Ocean Phys., 25, 1150-1156.

Bals-Elsholtz, T., E. H. Atallah, L. F. Bosart, T. A. Wasula, M. J. Cempa, and A. R. Lupo, 2001: The wintertime Southern Hemisphere split jet: Structure, variability, and evolution. J. Climate, 14, 4191-4215.

Chen, W. Y., and H. M. van den Dool, 1997: Asymmetric impact of tropical SST anomalies on atmospheric internal variability over the North Pacific. J. Atmos. Sci., 54, 725-740.

Dole, R. M., and N. D. Gordon, 1983: Persistent anomalies of the extra-tropical Northern Hemisphere wintertime circulation. Geographical distribution and regional persistence characteristics. Mon. Wea. Rev., 111, 1567-1586.

Fournier, A., 2000: Orthonormal wavelet analysis with a shift equivariance, with an application to observed atmospheric-blocking spatial structure. J. Atmos. Sci., 57, 3856-3880.

Frederiksen, J. S., 1982: A unified three-dimensional instability theory of the onset of blocking and cyclogenesis. J. Atmos. Sci., 39, 969-982.

—_, 2000: Singular vectors, finite-time normal modes, and error growth during blocking. J. Atmos. Sci., 57, 312-333.

Gruza, G. V., and L. V. Korovkina, 1991a: Seasonal features of spatial distribution of blocking indicies in the Northern Hemisphere. Meteor. Hydrol., 3, 108-110.

$\longrightarrow$, and - , 1991b: Climatic monitoring of western transfer blocking processes in the Northern Hemisphere. Meteor. Hydrol., 8, 11-17.

Hurrell, J. W., H. van Loon, and D. J. Shea, 1995: The mean state of the troposphere. National Center for Atmospheric Research Tech. Memo. NCAR/CAS/95-08, 80 pp.

Kalnay, E., and Coauthors, 1996: The NCEP/NCAR 40-year reanalysis project. Bull. Amer. Meteor. Soc., 77, 437-471.

Kalnay-Rivas, E., and L. O. Merkine, 1981: A simple mechanism for blocking. J. Atmos. Sci., 38, 2077-2091.

Kayano, M. T., 1999: Southeastern Pacific blocking episodes and their effect on South American weather. Meteor. Atmos. Phys., 69, $145-155$.

Key, J. R., and A. C. K. Chan, 1999: Multidecadal global and regional trends in $1000 \mathrm{mb}$ and $500 \mathrm{mb}$ cyclone frequencies. Geophys. Res. Lett., 26, 2053-2056.

Kidson, J. W., 2000: An analysis of New Zealand synoptic types and their use in defining weather regimes. Int. J. Climatol., 20, 299316.

Konrad, C. E., and S. J. Colucci, 1988: Synoptic climatology of 500$\mathrm{mb}$ circulation changes during explosive cyclogenesis. Mon. Wea. Rev., 116, 1431-1443.

Lejenas, H., 1984: Characteristics of Southern Hemisphere blocking as determined from a time series of observational data. Quart. J. Roy. Meteor. Soc., 110, 967-979.

, and H. Okland, 1983: Characteristics of Northern Hemisphere 
blocking as determined from a long time series of observational data. Tellus, 35A, 350-362.

— blocking. Mon. Wea. Rev., 120, 2821-2830.

Lupo, A. R., 1997: A diagnosis of two blocking events that occurred simultaneously over the midlatitude Northern Hemisphere. Mon. Wea. Rev., 125, 1801-1823.

— , and P. J. Smith, 1995a: Climatological features of blocking anticyclones in the Northern Hemisphere. Tellus, 47A, 439-456.

$\longrightarrow$, and $\longrightarrow$ 1995b: Planetary and synoptic-scale interactions during the life cycle of a mid-latitude blocking anticyclone over the North Atlantic. Tellus, 47A, 575-596.

_ and _ 1998: The interactions between a midlatitude blocking anticyclone and a synoptic-scale cyclone occurring during the summer season. Mon. Wea. Rev., 126, 503-515.

_ continental blocking. Quart. J. Roy. Meteor. Soc., 125, 107-138.

_ , R. J. Oglesby, and I. I. Mokhov, 1997: Climatological features of blocking anticyclones: A study of Northern Hemisphere CCM1 model blocking events in present-day and double $\mathrm{CO}_{2}$ concentration atmospheres. Climate Dyn., 13, 181-195.

Marques, R. F. C., and V. B. Rao, 1999: A diagnosis of a long-lasting blocking event over the Southeast Pacific Ocean. Mon. Wea. Rev., 127, 1761-1776.

$\longrightarrow$, and — 2000: Interannual variations of blockings in the Southern Hemisphere and their energetics. J. Geophys. Res., 105, $4625-4636$.

Mokhov, I. I., and V. K. Petukhov, 1997: Blockings and their tendencies of change. Doklady, Trans. Russ. Acad. Sci., 357, 687689.

— , and E. A. Tikhonova, 2000: Atmospheric blocking characteristics in the Northern Hemisphere: Diagnostics of changes. Research Activities in Atmospheric and Ocean Modeling, WMO/ TD-987, 1 p.

— - — A. R. Lupo, and J. M. Wiedenmann, 2001: Atmospheric blocking characteristics in the Northern Hemisphere: A comparison of two climatologies. Research Activities in Atmospheric and Ocean Modeling, WMO/TD-1064, 1 p.

Nakamura, H., M. Nakamura, and J. L. Anderson, 1997: The role of high- and low-frequency dynamics and blocking formation. Mon Wea. Rev., 125, 2074-2093.

Neter, J., W. Wasserman, and G. A. Whitmore, 1988: Applied Statistics. 3d ed. Allyn and Bacon Press, 1006 pp.

Nicholls, N., 2001: The insignificance of significance testing. Bull. Amer. Meteor. Soc., 82, 981-986.

Pielke, R. A., Jr., and C. N. Landsea, 1999: La Nina, El Nino, and Atlantic hurricane damages in the United States. Bull. Amer. Meteor. Soc., 80, 2027-2034.

Quiroz, R. S., 1987: Travelling waves and regional transitions in blocking activity in the Northern Hemisphere. Mon. Wea. Rev., 115, 919-935.
Renwick, J. A., 1998: ENSO-related variability in the frequency of South Pacific blocking. Mon. Wea. Rev., 126, 3117-3123.

_ , and J. M. Wallace, 1996: Relationships between North Pacific wintertime blocking, El Nino, and the PNA pattern. Mon. Wea. Rev., 124, 2071-2076.

—_, and M. J. Revell, 1999: Blocking over the South Pacific and Rossby wave propagation. Mon. Wea. Rev., 127, 2233-2247.

Rex, D. F., 1950: Blocking action in the middle troposphere and its effect on regional climate II: The climatology of blocking action. Tellus, 3, 275-301.

Shabbar, A., J. Huang, and K. Higuchi, 2001: The relationship between the wintertime North Atlantic Oscillation and blocking episodes in the North Atlantic. Int. J. Climatol., 21, 355-369.

Shukla, J., and K. C. Mo, 1983: Seasonal and geographical variation of blocking. Mon. Wea. Rev., 111, 388-402.

Shutts, G. J., 1983: The propagation of eddies in diffluent jet streams: Eddy vorticity forcing of blocking flow fields. Quart. J. Roy. Meteor. Soc., 109, 737-761.

__ 1986: A case study of eddy forcing during an Atlantic blocking episode. Advances in Geophysics, Vol. 29, Academic Press, 135161.

Sinclair, M. R., 1996: A climatology of anticyclones and blocking for the Southern Hemisphere. Mon. Wea. Rev., 124, 245-263.

_ J. A. Renwick, and J. W. Kidson, 1997: Low-frequency variability of Southern Hemisphere sea level pressure and weather system activity. Mon. Wea. Rev., 125, 2531-2543.

Smith, S. R., and J. J. O'Brien, 2001: Regional snowfall distributions associated with ENSO: Implications for seasonal forecasting. Bull. Amer. Meteor. Soc., 82, 1179-1191.

Swanson, K. L., 2001: Blocking as a local instability to zonal varying flows. Quart. J. Roy. Meteor. Soc., 127, 1341-1357.

Tibaldi, S., E. Tosi, A. Navarra, and L. Pedulli, 1994: Northern and Southern Hemisphere seasonal variability of blocking frequency and predictability. Mon. Wea. Rev., 122, 1971-2003.

Triedl, R. A., E. C. Birch, and P. Sajecki, 1981: Blocking action in the Northern Hemisphere: A climatological study. Atmos.Ocean, 19, 1-23.

Trenberth, K. E., and K. C. Mo, 1985: Blocking in the Southern Hemisphere. Mon. Wea. Rev., 113, 3-21.

Tsou, C. H., and P. J. Smith, 1990: The role of synoptic/planetaryscale interactions during the development of a blocking anticyclone. Tellus, 42A, 174-193.

van Loon, H., 1956: Blocking action in the Southern Hemisphere. Notos, 5, 171-177.

Vincent, D. G., 1994: The South Pacific Convergence Zone (SPCZ): A review. Mon. Wea. Rev., 122, 1949-1970.

Watson, J. S., and S. J. Colucci, 1999: Is there a connection between Northern Hemisphere blocking and ENSO? Preprints, Eighth Conf. on Climate Variations, Denver, CO, Amer. Meteor. Soc., 30-33.

Wright, A. D. F., 1974: Blocking action in the Australian region. Tech Rep. 10, Department of Science, Bureau of Meteorology, Canberra, Australia, $29 \mathrm{pp}$. 